intensity". The third patient was not helped by the treatment. The length of the follow up period was only five months. These results surely do not warrant such a dogmatic and optimistic conclusion. This needs to be said as we are being told on the one hand that pimozide is a therapeutically effective drug for such patients, and now that pimozide plus behaviour therapy or behaviour therapy alone can work the miracle. A larger number of patients, stringently defined inclusion criteria, controlled studies and a much longer follow up period are required before any such claim can be made.

\section{George Hay}

Consultant Psychiatrist,

University Hospital of South Manchester,

West Didsbury M20 8LR

\section{DIAGNOSTIC USE OF SLEEP DEPRIVATION DEAR SIR,}

It is generally agreed that the improvement in mood that follows Sleep Deprivation (SD) in depressed patients is usually short-lived (Post et al, 1976). For this reason, the therapeutic use of SD has been questioned (Knowles et al, in press).

There is, however, one use of SD which has received no mention in the literature, that is, as an aid to diagnosis. In our experience, SD can be decisive in clarifying the sometimes very difficult differential diagnosis between depression and dementia. We have studied a series of such cases referred, because the diagnosis was obscure, to the Treatment Evaluation Unit, Kingston Psychiatric Hospital. In some cases, one 40-hour period of SD resulted in a complete reversal of mood and a dramatic return to normal intellectual function. The duration of this reversal, though it may be brief, is usually long enough to allow psychometric testing to be done to determine whether there is intellectual deterioration. When faced with such a diagnostic question, it is also clinically useful to have a measure of the degree of recovery that is attainable, thus setting a goal for subsequent treatment. Knowing that the syndrome can be reversed has allowed us to undertake treatment with a more precise indication and with greater confidence in the results than would have been possible otherwise.

\section{F. J. J. LETEMENDIA}

A. Prowse

\section{S. SOUTHMAYD}

Kingston Psychiatric Hospital, Kingston, Ontario K7L 4X3, Canada

\section{References}

Post, R. M., Kotin, J. \& Goodwin, F. K. (1976) Effects of sleep deprivation on mood and central amine metabolism in depressed patients. Archives of General Psychiatry, 33, 627-32.
Knowles, J. B., Southmayd, S. E., Delva, N., Prowse, A., Maclean, A., Cairns, J., Letemendia, F. \& WALDRON, J. (1981) Sleep deprivation: outcome of controlled single case studies of depressed patients. Canadian Journal of Psychiatry. (In press).

\section{ADOPTION RESEARCH IN SCHIZOPHRENIA}

DeAr Sir,

I was involved recently in the adoption of the baby of a sixteen-year-old schizophrenic, whose own mother had also suffered from schizophrenia. The social workers explained that the adopting parents were entitled to the background information about the baby's origins, and I agreed to meet them. Questions were asked about the heritability of schizophrenia, and even what signs to look out for in adolescence in the unfortunate event that the daughter should develop the illness. I realized that the child entered its family trailing a background of schizophrenia, and would be watched closely all its life to see if the hereditary taint would show itself in abnormality.

What is the bearing of this on the adoption research from Oregon and Denmark (see Gottesman, 1978), which I had thought represented cast-iron evidence for schizophrenia being to a substantial extent truly inherited by genetic mechanisms? If there was some transmission of background information to the adopting parents, as can occur in this country, did it invalidate the aim of the research to separate genetic and environmental influences on the children studied?

Greenwich District Hospital,

ANDREW C. SMrTH

Vanbrugh Hill,

London SE10 9HE

\section{Reforence}

I. I. Gotresman (1978) Schizophrenia and genetics: Where are we? Are you sure? In The Nature of Schizophrenia-New Approaches to Research and Treatment (eds. L. C. Wynne, R. L. Cromwell and S. Matthysse). New York: Wiley. Pp 59-75.

\section{EARLY AGE OF ONSET OF PSYCHIATRIC DISORDER AND THE PROPORTION OF ILL RELATIVES}

Dear Str,

Family studies of psychiatric disorders have consistently revealed higher rates of morbidity in the relatives of patients with an earlier onset of disorder. From a review of 18 studies, we recently noted that this relationship appeared to be nonspecific and held for affective disorders in general, bipolar and unipolar subtypes, alcoholism, and possibly schizophrenia. In an almost repetitive fashion, several authors concluded that a stronger or independent genetic component was involved in the etiology of early onset disorders, 